\title{
A study of the impact of caregiver personality and family structure on the social maturity of children with mild intellectual disability
}

\author{
Juhi Gupta ${ }^{1}$ \\ ${ }^{1}$ Post graduate student, Department of Psychology, Maniben Nanavati Women's College, Mumbai. \\ E-mail-juhirgupta@gmail.com
}

\begin{abstract}
Background: Caregiver personality and family styles have a major role in the upbringing and personality development of children in the family. The major purpose of this study was to investigate the difference in social maturity scores of children with mild intellectual disability raised in a joint family and nuclear family and to study the difference in social maturity scores of these children with primary caregivers possessing introvert and extrovert personality characteristics.

Methodology: The study used a purposive sampling method to study sixty-one children raised care-givers who were either introverts or extroverts and coming from both joint and nuclear family structure. The children were administered the Vineland Social Maturity Scale and caregivers were administered the Introversion Scale. The study used a sample with a wide age range, ANCOVA was used to keep the age as a covariate.

Results: Results indicated that contrary to expectations, introvert care givers were more likely to raise children with greater social maturity $(\mathrm{p}=0.029)$ and that family type whether joint or nuclear, had no effect on the social maturity of the child as measured by the Vineland Social Maturity Scale.

Conclusions: Family constellation and caregiver personality type do play a role in the social development of a child with intellectual disability though further studies in this direction are warranted.
\end{abstract}

Keywords: intellectual disability, family, joint family, nuclear family, personality, caregiver, social maturity.

(Paper received $-13^{\text {th }}$ June 2016 , Peer review completed $-25^{\text {th }}$ July 2016 , Accepted $-4^{\text {th }}$ August 2016)

\section{INTRODUCTION}

Various factors affect the social functioning of children with intellectual disability. There are several studies suggesting that children with mild intellectual disability are particularly amenable to imitative learning [1]. Studies have suggested that since children with mild intellectual disability tend to have limited cognitive abilities and might experience a history of failure in the use of their cognitive abilities, they tend to exhibit an outer-directed cognitive style as a function of frequent failure and a consequent high expectancy for failure [2]. It has been concluded that intellectually disabled children have difficulty ignoring irrelevant dimensions, tend to have an initial inability to pay attention to relevant cues and have deficits in short-term memory [3]. Procedures of modeling would seem to compensate for the retarded children's deficits in attention, wherein this procedure deliberately helps to utilize and focus an observer's attention to the relevant cues or behaviors and eliminates distracting or competing cues [4]. Due to their intellectual or cognitive deficits, these children need more concrete materials in their learning suggesting that exposure to observable behavior of model would be quite beneficial for them. Observers who lack conceptual skills benefit a great deal from behavioral modeling [5]. 


\section{Definitions for the current study}

Caregiving: Caregiving is referred to as 'the act of providing unpaid assistance and support to family members or acquaintances who have physical, psychological or developmental need' [6].

Joint Family: According to Kapadia [7], a joint family is 'a group formed not only of a couple and their children but also other relations either from father's side or from mother's side depending on whether the joint family is patrilineal or matrilineal'.

Nuclear Family: Desai [8] refers to nuclear family as 'a husband and wife with or without unmarried children'.

Social Maturity: 'Social maturity is the ability to function in an appropriate manner and to understand the social rules and norms in place in a given culture and the ability to use that knowledge effectively' [9].

Personality: Allport [10] referred to personality as 'a dynamic organization within the individual of those psychophysical systems that determine his unique adjustments to the environment'.

Authors have examined the relationship between adaptive behavior of deinstitutionalized intellectually disabled persons and aspects of their environment and found that individual characteristics, particularly level of retardation and additional disabilities, were the strongest predictors of adaptive behavior. But, after controlling for the effects of this powerful set, it was evident that community variables such as aspects of the residence, neighborhood and community, were significantly related to adaptive behavior [11]. Researchers have studied the correlation of social competence among mildly mentally school-aged children retarded and hypothesized that preschool experience would contribute significantly to competence following language and then I.Q. [12]. A study designed to identify the effects of severity of retardation, age, type of services attended and location of services in rural-urban areas on the social development of children with intellectual disability, found that with increasing severity of retardation, social development also decreases [13].

\section{METHODOLOGY}

The method of purposive sampling was utilized for the study. Sixty one children suffering from mild intellectual disability (IQ below 70) from the age group of 2-15 years were chosen from special schools in Mumbai. An approximately equal number of children were chosen from joint and nuclear families and an equal number of children were also chosen on the basis of their primary caregivers who possessed introvert or extrovert personality characteristics.

\section{Apparatus and Materials}

Vineland Social Maturity Scale (VSMS): The Vineland social maturity scale was originally devised by Doll in 1935 and was adapted by Malin [14]. It can be used for the age group of 0-15 years and contains 89 items. This scale consists of 8 subscales namely- Self-Help General (e.g. asks to go to the toilet, tells time to quarter hour); Self-Help Eating (e.g. drinks from cup or glass unassisted, uses table knife for spreading) ;Self-Help Dressing (e.g. dries own hands, exercises own care of dress) ; Self-Direction (e.g. is trusted with money, buys own clothing accessories) ; Occupation (e.g. uses skates, sled, wagon, performs responsible routine chores) ; Communication (e.g. uses names of familiar objects, communicates by letter) ; Locomotion(e.g. moves about on the floor, walks downstairs) ; Socialization (e.g. plays with other children, plays difficult games). The reliability of this scale was found to be 0.95 and validity of this scale was found to be 0.91 .

Introversion scale: The Introversion scale developed by McCroskey [15] and is found to have sound psychometric properties

The researcher chose a sample of 61 children suffering from mild intellectual disability on the basis of the family structure (joint or nuclear family) and personality characteristics of the primary caregiver (introversion or extroversion) from special schools of Mumbai. The primary caregivers of children with 
mild intellectual disability were administered with an Introversion scale followed by the Vineland Social Maturity Scale to evaluate the social maturity of children with mild intellectual disability. The design of this study was $2 \times 2$ factorial.

The independent variables of the study were the type of family structure i.e. Nuclear or Joint/Extended family; personality characteristics of the primary caregiver i.e. Extroversion and Introversion as measured by Introversion scale. The dependent variable was the score on Vineland Social Maturity Scale

\section{Hypotheses}

1. There will be a significant difference in the social maturity scores of children suffering from mild intellectual disability whose primary caregivers possess extrovert personality characteristics.

2. There will be a significant difference in the social maturity scores of children raised in a joint family, as compared to those raised in a nuclear family.

\section{STATISTICAL ANALYSIS}

The data was analyzed using two-way ANCOVA and 2x2 factorial design was used for the study since there were two independent variables with two levels each. A two-way ANCOVA was conducted to determine a statistically significant difference between Type of family structure (Joint and Nuclear Family), Personality characteristics of the primary caregiver (Extroversion and Introversion) on the dependent variable of Social Maturity based on Vineland Social Maturity controlling for age. All the statistics were computed using computerized statistical software.

\section{RESULTS}

There were 29 primary caregivers with extrovert personality characteristics and 32 caregivers with introvert personality characteristics. It also shows 26 children belonging to joint families and 35 children belonging to nuclear families.

Table 1: Mean and standard deviations for Social Maturity scores across personality types (extroverts, introverts) and family structures (joint, nuclear)

\begin{tabular}{|ccccc|}
\hline Personality Type & $\begin{array}{c}\text { Family } \\
\text { Type }\end{array}$ & Mean & $\begin{array}{c}\text { Standard } \\
\text { Deviation }\end{array}$ & $\mathrm{N}$ \\
\hline Extrovert & Joint & 55.17 & 21.821 & 12 \\
\hline & Nuclear & 82.18 & 44.52 & 17 \\
\hline & Total & 71 & 38.768 & 29 \\
\hline Introvert & Joint & 95.29 & 43.315 & 14 \\
\hline & Nuclear & 85.83 & 32.466 & 18 \\
\hline & Total & 89.97 & 37.249 & 32 \\
\hline Total & Joint & 76.77 & 40.014 & 26 \\
\hline & Nuclear & 84.06 & 38.251 & 35 \\
\hline & Total & 80.95 & 38.852 & 61 \\
\hline
\end{tabular}

Table 2 shows that the covariate age does not significantly predict the social quotient. Therefore the current age shows no influence to the subject's social quotient. Interestingly, when age as a factor is not considered, the data shows that the personality structure of the care-giver has an impact on the social quotient of the child and not the family structure. There is no need to perform Post-Hoc test as there are only two personality types. On the basis of the mean scores, it can be concluded that children with primary 
caregivers with extrovert personality characteristics had lower social quotient as compared to children with caregivers who exhibited introvert personality characteristics. Based on the results the following outcomes have occurred. There is a significant effect of personality type on Social Maturity (SQ) after controlling for age, $\mathrm{F}(1,1)=5.109, \mathrm{p}=0.029$. The results indicate that SQ is higher for those children who have caregivers with introvert personality. There is no significant effect of family type on Social Maturity (SQ) after controlling for age, $\mathrm{F}(1,1)=0.828, \mathrm{p}=0.367$.

Table 2: ANCOVA for the variables

\begin{tabular}{|ccccccc|}
\hline Source & $\begin{array}{c}\text { Type III } \\
\text { sum of } \\
\text { squares }\end{array}$ & df & $\begin{array}{c}\text { Mean } \\
\text { squares }\end{array}$ & F & p value & $\begin{array}{c}\text { Partial } \\
\text { Eta } \\
\text { Squared }\end{array}$ \\
\hline $\begin{array}{c}\text { Corrected } \\
\text { model }\end{array}$ & $11432.558^{*}$ & 4 & 2858.14 & 2.023 & 0.104 & 0.126 \\
\hline Intercept & 43797.836 & 1 & 43797.836 & 30.993 & 0 & 0.356 \\
\hline Age & 123.2 & 1 & 123.2 & 0.087 & 0.769 & 0.002 \\
\hline $\begin{array}{c}\text { Personality } \\
\text { type }\end{array}$ & 7092.475 & 1 & 7092.475 & 5.019 & $0.029^{*}$ & 0.082 \\
\hline $\begin{array}{c}\text { Family } \\
\text { type }\end{array}$ & 1170.785 & 1 & 1170.785 & 0.828 & 0.367 & 0.015 \\
\hline $\begin{array}{c}\text { Personality } \\
\text { type } \\
\text { *Family } \\
\text { type }\end{array}$ & 4657.949 & 1 & 4657.949 & 3.296 & 0.075 & 0.056 \\
\hline Error & 79136.294 & 56 & 1413.148 & & & \\
\hline Total & 490304 & 61 & & & & \\
\hline $\begin{array}{c}\text { Corrected } \\
\text { Total }\end{array}$ & 90568.852 & 60 & & & & \\
\hline
\end{tabular}

*significant $(\mathrm{p}<0.05)$

\section{DISCUSSION}

Intellectual disability is by definition bi-dimensional involving both low intelligence and impaired behaviour and thus the criteria most often used to define intellectual disability are social competence and ability to assume certain personal and social responsibilities, school performance and performance on intelligence tests [16]. The researcher predicted that the extended family structure in comparison with nuclear family structure would result in higher social maturity score of the mild intellectually disabled child. However, the obtained findings showed no effect of the family structure on the social maturity score of the child. Also, since it was expected that the caregivers with extrovert personality may be sociable, outgoing, gregarious and socially competent and that they tend to be more active and directive in their approach while dealing with the world, the researcher predicted that this personality type would influence their children, thereby resulting in their high social maturity score. However, the findings of this study did not show such a trend in the social maturity score of the retarded child. Instead an opposite trend, that is the introvert personality type of the caregiver showed an impact on the social maturity score of the child, only when age was considered as a covariant factor.

These finding was consistent with a research that stated six advantages of being an Introvert. It was stated that how introversion was not a defect but instead involved a careful, sensitive temperament that brought enhanced creativity and a unique brand of leadership and empathy. Introverts are highly effective influencers when they stop trying to act like extroverts and instead make the most of their natural strengths. The strengths that they embrace are taking quiet time, preparing, listening, having focused conversations, writing and using social media [17]. 
Apart from family structure and personality characteristics of the primary caregiver, research shows that culture also plays a role in the social development of a child. Importantly, the form that behaviors take may appear identical across cultures. Yet, given that cultures vary in their customs and beliefs, the same behavior may be interpreted differently across cultures. It is likely that any behavior that is viewed, within a culture, as adaptive will lead to its encouragement by significant others including parents and peers; in contrast, if a behavior is perceived to be maladaptive, it will be discouraged researchers typically discuss two cultural phenomena: (1) independent, individualistic, or Western cultures, and (2) interdependent, collectivistic, or Eastern and Southern (e.g., Central and South American) cultures. Western cultures are often described as those for whom members value assertiveness, expressiveness and competitiveness; whereas Eastern and Southern cultures are often described as those for whom members value group harmony and cooperation [18-19].

Indian society has been dominated by collectivistic culture since ages and the concept of extended family structure is religiously followed. In collectivistic societies, children are encouraged to view difficulties as a group issue and are made aware of their responsibilities to their family and community. This is why family type was also considered as a variable in this study. Some other reasons why the results of this study contravene other researches could be the limited number of participants taken for the study. Another possibility may be that only those children available at the time of data collection were taken for this research. Next possibility for the rejection of the hypothesis may be that the gender of the child, as a control variable, was not held constant. There were unequal numbers of subjects in each category of the study. Ordinal position of the child in their respective families and education levels of caregivers were not considered as a controlling factor.

Care givers with introvert personality were more likely to improve social maturity in the population studied. The results also revealed that their family structure, joint or nuclear, did not show any difference in their social maturity scores.

\section{REFERENCES}

1. Harris JC. Intellectual disability: Understanding its development, causes, classification, evaluation, and treatment. Oxford University Press; 2006.

2. Taylor JL, Lindsay WR, Willner P. CBT for people with intellectual disabilities: emerging evidence, cognitive ability and IQ effects. Behav Cogn Psychother 2008;36(06):723-33.

3. Vicari S, Carlesimo GA. Short-term memory deficits are not uniform in Down and Williams syndromes. Neuropsychol Rev 2006;16(2):87-94.

4. Murdock BB. Short-term memory. Psychol Learn Motiv 1972;5:67-127.

5. Wade C, Llewellyn G, Matthews J. Modeling contextual influences on parents with intellectual disability and their children. Am J Intellect Dev Disabil 2011;116(6):419-37.

6. Drentea P, Goldner MA. Caregiving outside of the home: The effects of race on depression. Ethnicity Health 2006;11(1):41-57.

7. Kapadia KM. Marriage and family in India. Bombay: Oxford University Press; 1966.

8. Lloyd CB, Desai S. Children's living arrangements in developing countries. Population Res Pol Rev 1992;11(3):193-216.

9. Smith PK. A longitudinal study of social participation in preschool children: Solitary and parallel play reexamined. Developm Psychol 1978;14(5):517-30.

10. Allport GW. Personality. New York: Holt; 1937.

11. Schalock RL, Luckasson RA, Shogren KA. The renaming of mental retardation: Understanding the change to the term intellectual disability. Intellect Dev Disabil 2007;45(2):116-24.

12. Dagnan D, Sandhu S. Social comparison, self-esteem and depression in people with intellectual disability. J Intellect Disabil Res 1999;43(5):372-9.

13. Kumar I, Singh AR, Akhtar S. Social development of children with mental retardation. Industr Psychiatry J 2009;18(1):56-62.

14. Doll EA. Vineland social maturity scale: Condensed manual of directions. American Guidance Service; 1965.

15. Richmond VP, McCroskey JC. Communication: Apprehension, avoidance, and effectiveness. Pearson College Division; 1997. 
16. Schalock RL, Borthwick-Duffy SA, Bradley VJ, Buntinx WH, Coulter DL, Craig EM, Gomez SC, Lachapelle Y, Luckasson R, Reeve A, Shogren KA. Intellectual disability: Definition, classification, and systems of supports. American Association on Intellectual and Developmental Disabilities; 2010.

17. Cain S. Quiet: The power of introverts in a world that can't stop talking. Broadway Books; 2013.

18. Blacher J, McIntyre LL. Syndrome specificity and behavioural disorders in young adults with intellectual disability: Cultural differences in family impact. J Intellect Disabil Res 2006;50(3):184-98.

19. Blacher J, Baker BL. Positive impact of intellectual disability on families. Am J Mental Retard 2007;112(5):330-48.

\author{
Acknowledgements - Nil \\ Source of Funding - Nil \\ Conflict of Interest - Nil
}

